\title{
Small-volume Lu-Hf and U-Pb Isotope Determination of Complex Zircons by Solution and Laser Ablation MC-ICP-MS
}

\author{
Ann Bauer ${ }^{1}$ and Matthew Horstwood ${ }^{2}$ \\ ${ }^{1}$ University of Wisconsin-Madison, Madison, Wisconsin, United States, ${ }^{2}$ British Geological Survey, \\ Keyworth, England, United Kingdom
}

We present analysis methods for coupled solution and laser ablation $\mathrm{Lu}-\mathrm{Hf}$ and $\mathrm{U}-\mathrm{Pb}$ isotope analyses of zircon, with a focus on low-volume sampling (e.g. Bast et al., 2015; d'Abzac et al., 2016). These techniques allow for the robust analysis of domains ultimately corresponding to 20-40 nanograms of complex zircons, which is critical in cases where age zonation could result in the decoupling of $\mathrm{U}-\mathrm{Pb}$ and Lu-Hf isotope information (Harrison et al., 2005), potentially producing spurious initial Hf isotopic results (e.g. Amelin et al., 2000; Valley et al., 2005). We investigated the potential for matrix effects, possible methods of $\mathrm{Yb}$ interference correction, and the accurate determination of ${ }^{176} \mathrm{Lu} /{ }^{177} \mathrm{Hf}$ for both solution and laser ablation methods. We perform consecutive U-Pb and Lu-Hf isotopic analyses, which results in a pit depth of $\sim 18 \mu \mathrm{m}$ and total spot size of $\sim 25 \mu \mathrm{m}$, excavating just $\sim 40 \mathrm{ng}$ of zircon. We demonstrate, however, that appropriate levels of uncertainty can be achieved on just $\sim 20 \mathrm{ng}$ total of ablated zircon. This reduced-volume laser ablation protocol offers a lower-volume alternative to laser ablation split-stream analysis (e.g. Ibañez-Mejia et al., 2015). Additionally, we demonstrate the capability to determine the Hf isotope composition of an equivalent volume of zircon using solution MC-ICP-MS, as well as the suitability of analyzing solutions that have not been subject to Hf-HREE separation (Münker et al., 2001). We optimized the sample introduction protocols for the solution measurements so that they were introduced to the mass spectrometer in just $100 \mu \mathrm{L}$ of solution; this resulted in one order of magnitude improvement in minimum sample size versus conventional approaches. The solution and laser ablation analyses in this study were achieved with comparable total sample volume and levels of uncertainty, using just $0.3 \mathrm{ng}$ of Hf while achieving uncertainties on the order of $1 \varepsilon_{\mathrm{Hf}}$ unit. Our successive low-volume U$\mathrm{Pb}$ and $\mathrm{Lu}-\mathrm{Hf}$ laser ablation method is applied to detrital zircons from the Zimbabwe Craton and our solution method is demonstrated for microsampled granitic zircons. These specific applications highlight the utility of these methods for complex zircons.

\section{References}

Amelin, Y., Lee, D. C., \& Halliday, A. N. (2000). Early-middle Archaean crustal evolution deduced from $\mathrm{Lu}-\mathrm{Hf}$ and $\mathrm{U}-\mathrm{Pb}$ isotopic studies of single zircon grains. Geochimica et Cosmochimica Acta, 64(24), 42054225.

Bast, R., Scherer, E. E., Sprung, P., Fischer-Gödde, M., Stracke, A., \& Mezger, K. (2015). A rapid and efficient ion-exchange chromatography for $\mathrm{Lu}-\mathrm{Hf}, \mathrm{Sm}-\mathrm{Nd}$, and $\mathrm{Rb}-\mathrm{Sr}$ geochronology and the routine isotope analysis of sub-ng amounts of $\mathrm{Hf}$ by MC-ICP-MS. Journal of analytical atomic spectrometry, 30(11), 2323-2333.

d'Abzac, F. X., Davies, J. H., Wotzlaw, J. F., \& Schaltegger, U. (2016). Hf isotope analysis of small zircon and baddeleyite grains by conventional multi collector-inductively coupled plasma-mass spectrometry. Chemical Geology, 433, 12-23.

Harrison, T. M., Blichert-Toft, J., Müller, W., Albarede, F., Holden, P., \& Mojzsis, S. J. (2005). Heterogeneous Hadean hafnium: evidence of continental crust at 4.4 to $4.5 \mathrm{Ga}$. Science, 310(5756), 19471950. 
Ibañez-Mejia, M., Pullen, A., Arenstein, J., Gehrels, G. E., Valley, J., Ducea, M. N.,Mora, A.R., Pecha, M., \& Ruiz, J. (2015). Unraveling crustal growth and reworking processes in complex zircons from orogenic lower-crust: The Proterozoic Putumayo Orogen of Amazonia. Precambrian Research, 267, 285310.

Münker, C., Weyer, S., Scherer, E., \& Mezger, K. (2001). Separation of high field strength elements ( $\mathrm{Nb}, \mathrm{Ta}, \mathrm{Zr}, \mathrm{Hf}$ ) and Lu from rock samples for MC-ICPMS measurements. Geochemistry, Geophysics, Geosystems, 2(12).

Valley, J. W., Cavosie, A. J., Fu, B., Peck, W. H., \& Wilde, S. A. (2006). Comment on" Heterogeneous Hadean Hafnium: Evidence of Continental Crust at 4.4 to 4.5 Ga". Science, 312(5777), 1139-1139. 